\title{
Shallow subsurface imaging of the Wagad active fault system (Kachchh, northwestern India) by time domain electromagnetic studies
}

\author{
G Pavan Kumar*, Maul Nagar, Virendar Choudhary and A Durga Prasad \\ Institute of Seismological Research, Raisan, Gandhinagar 382007, India. \\ *Corresponding author.e-mail: gayatripavan@isr.res.in
}

MS received 7 July 2017; revised 20 June 2018; accepted 25 June 2018; published online 11 March 2019

The Kachchh rift basin (KRB) in the northwestern Indian shield is one of the most seismically active intraplate regions of the world. It has witnessed four large earthquakes in the past two centuries that leads the region most vulnerable for seismic hazard. For effective seismic hazard assessment, detailed information on faults and its subsurface geometry is essential. Recently, shallow subsurface geophysical studies, particularly electrical resistivity studies have become a successful practice in imaging of fault zones and their attribute. In the present study, we carried out the time domain electromagnetic (TDEM) investigations across the Wagad highland of eastern KRB to map shallow subsurface structure and imaging fault zones in terms of resistivity. Resistivity section obtained after combining one dimensional models of 21 sites display significant details of the fault structures and geometry of shallow basin infill down to $200 \mathrm{~m}$. The shallow layer of the basin infill across the South Wagad fault (SWF) and the North Wagad fault has a wedge shape made of unconsolidated deposits with thickness of $\sim 15-20 \mathrm{~m}$. We infer that it might be due to syntectonic sedimentation due to the footwall subsidence across a branch fault of the SWF. The section indicates a $\sim 60-65$ and 50-55 m estimates of cumulative throws for the SWF and NWF, respectively. Across the Gedi fault, the section indicates least block displacements, which might either be due to dominate strike-slip nature of faulting or more activeness of NWF compared to GF during the recent geological past. The results from the study affirm the ongoing Holocene deformation in the region signifying active nature of these faults.

Keywords. Time domain electromagnetics; resistivity; active faults; Kachchh.

\section{Introduction}

The Kachchh rift basin (KRB) (figure 1) in the western most part of India is one of the most seismically active intraplate regions of the world (Kayal et al. 2002; Biswas 2005, 2016). The basin had experienced four large earthquakes in the past two centuries, which includes M 7.8 earthquake on the Allah Bund fault (1819); the M 6.3 earthquake on the Kachchh Mainland fault (KMF) (1845), the
M 6.1 Anjar earthquake (1956) and the widely destructive M 7.7 Bhuj earthquake (2001) on the step over fault zone near the South Wagad fault (SWF) (Rastogi et al. 2014; Talwani 2016). Many geophysical and geological investigations have been carried out after the 2001 earthquake. The studies inferred re-activation and branching of existing faults in the region (Biswas and Khattri 2002; Mandal et al. 2004, 2007; Biswas 2005; Patidar et al. 2007; Maurya et al. 2013; Rastogi et al. 2012, 


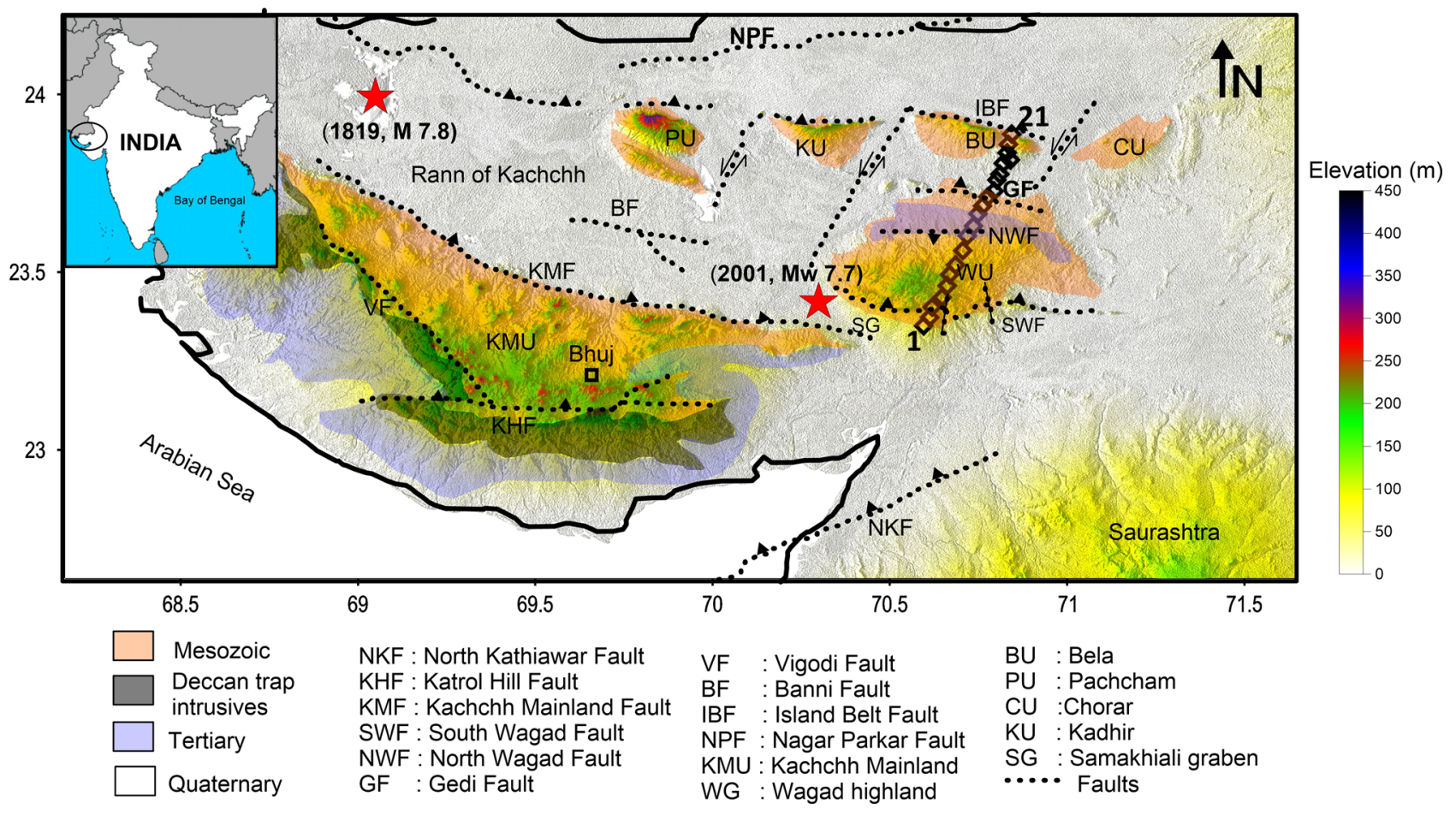

Figure 1. Map showing geological setup of the Kachchh basin superimposed on topography of the region (modified after Biswas and Deshpande 1970). The TDEM sounding locations are shown with the diamond symbols. The stars represent the location of the 1819 and 2001 earthquakes.

2014), particularly in the eastern part of the KRB. The current aftershock activity has been attributed to activity along these fault systems. Deep geophysical investigations are being carried out to understand the nature of the faults and mapping blind faults across the basin (Kayal et al. 2002; Mandal et al. 2004; Chandrasekhar et al. 2009, 2012; Naganjaneyulu et al. 2010; Pavan Kumar et al. 2017a, b). However, the amount of shallow geophysical surveys done in the region is very limited (Mithila and Bansal 2016) except Ground Penetrating Radar (GPR) studies. It is of considerable importance to explore the geological structure around active faults, especially near-surface unconsolidated layers, to estimate the faults activity. The information on active faults and its subsurface geometry is essentially needed for effective seismic hazard assessment.

Many active fault traces were identified in the region based on field (both geophysical and geological) investigations and satellite photo interpretation, which suggested imprints of Holocene to post Tertiary tectonic activity along the faults (Malik et al. 2001; Mathew et al. 2006; Patidar et al. 2007, 2008; Maurya et al. 2013; Rajendran et al. 2008; Chowksey et al. 2011; Bhattacharya et al. 2013; Kothyari et al. 2016). GPR studies by Patidar et al. (2007) indicated reactivation of the Kathrol Hill Fault (KHF) under compressive stress and suggested southward directed tilting of the geomorphic features due to neotectonic movements along the KHF. Further, the study revealed the splaying nature of the fault in Quaternary sediments (Patidar et al. 2008). Mandal et al. (2004, 2007) on the basis of passive seismology studies, identified an E-W trending blind thrust, named as North Wagad Fault (NWF), which is suggested to be the causative fault for the 2001 Bhuj earthquake. A GPR study by Maurya et al. (2013) infers that the Gedi fault (GF) is steep north dipping reverse fault, which becomes vertical at depth and is characterized by the moderate earthquake activity under a compressive stress regime. Morphometric analyses of North Wagad Fault (NWF) and the GF zones (Bhattacharya et al. 2013) suggested that the past and current seismicity associated with both the NWF and GF. They further inferred that the NWF seems to be more active compared to the GF. Recent electromagnetic imaging studies by Pavan Kumar et al. (2016) along the Anjar-Rapar corridor infers the anomalous behavior of the aquifer in the KHF and the SWF zones.

Recent studies suggest that the eastern Kachchh is a potential zone for major earthquakes in the 
near future (Biswas 2005; Rastogi et al. 2012; Mandal 2016; Pavan Kumar et al. 2017a,b). It is also evident from the concentration of earthquakes showing two prominent clustering around west and north of the Wagad region suggesting that this part of the basin is a highly strained zone with high seismic hazard potential (Mandal et al. 2007; Mandal 2016; Pavan Kumar et al. 2017a, b). The recognition and characterization of faults and its splays/branches in terms of geometry, type of movement and rates of activity are essential in understanding morphotectonics as well as assessing the seismic potential of a region. Identification of secondary faults, particularly assessment of their seismic potential, is sometimes difficult because of the poor conditions of surface exposure (concealment by bodies of water or young sediments, plastic deformation of near-surface materials). It is of considerable importance to geophysically explore the geological structure around the faults, especially subsurface unconsolidated layers, presence buried earthquake related structures for evaluation of activity along the fault. Further, for a realistic estimate of seismic hazard scenario, information on faults and its subsurface geometry (rupture length, dip and strike of fault) is essentially needed. In view of this, an attempt has been made to map the shallow subsurface resistivity structure between the SWF and GF in the Kachchh rift basin. We have applied time domain electromagnetic method (TDEM), which is an effective tool for exploring shallow subsurface structure down to several hundred meters, to image the lateral and vertical geological discontinuities across the fault zones and analyze in terms of activity of the region (Villani et al. 2015; Civico et al. 2017). Couple of deep electrical resistivity studies, particularly magnetotellurics (MT) surveys (Chandrasekhar et al. 2012; Pavan Kumar et al. 2017a,b) have been carried out in the region to understand the seismogenesis of the region as well architecture of the faults at crustal levels. However, the MT sections does not provide high resolution image at very shallow depths (down to 200-250 m). As the KRB has an average sedimentary (imaged as a conducting layer) thickness of $>2 \mathrm{~km}$ (Pavan Kumar et al. $2017 \mathrm{a}, \mathrm{b})$, the sharp resistivity contrast across the fault zones (imaged as conducting zone) with in the sedimentary layers may not resolved using broadband MT surveys. We therefore carried out TDEM studies in the region for the well resolved resistivity structure across the fault zones at shallow depths. The surficial expressions of the faults in some places of the Wagad region are concealed by recent Holocene deposits and difficult to image using conventional DC electrical imaging studies. The TDEM has proven to be an effective tool in mapping these concealed geological structures and can image the transposition of the various litho-units in terms of resistivity contrast (Pavan Kumar et al. 2016). Further, unveiling the nature of the shallow basin infill mainly from alluvial fans filling is very important in evaluating the role played by the active faults in its depositional evolution.

\section{Geology and tectonics of the study area}

North-south compression scenario in the KRB promotes reverse faulting on $\mathrm{E}-\mathrm{W}$ faults and strikeslip motion on transfer faults (Biswas 2005; Talwani 2016). The region consists primarily of six E-W striking faults, which bound three uplifts, and a few NW-SE and NE-SW striking transfer faults (figure 1). The major structural features of the region are bounded by the south-dipping Nagar Parker Fault (NPF) and the north-dipping North Kathiawar Fault (NKF) (figure 1). Other major faults in this region are the Allah Bund Fault (ABF), Kachchh Mainland Fault (KMF), Katrol Hill Fault (KHF), Banni Fault (BF), Vigodi Fault (VF), South Wagad Fault (SWF), Gedi Fault (GF) and North Wagad Fault (NWF) (Biswas and Khattri 2002; Mandal et al. 2004) (figure 1). The uplifted terrains in the region are: (1) the Island Belt Fault Zone; (2) the Kachchh Mainland highland, and (3) the Wagad highland. The Island Belt Fault Zone comprises four islands, viz. Pachchham, Khadir, Bela and Chorar. These islands are inferred to be controlled and separated by the right-lateral transverse and strike-slip faults (Biswas 2005).

The Mesozoic rocks are exposed on the uplifted land masses, while Tertiary rocks have occupied the structure lows within the basin. The Quaternary/Tertiary sediments, Deccan volcanic rocks and Jurassic sandstones resting on the Archean basement characterize the geological sequence of the Kachchh region (Biswas and Deshpande 1970). These sediments have a zone of the Deccan trap volcanic sandwiched between Jurassic rocks of the northern part and Eocene sediments in the south towards the coast. Limestone, shale and sandstone are the most common rocks in the region (Merh 1995). 


\subsection{The Wagad highland and SWF zone}

The Wagad region in the eastern Kachchh basin is delimited by the South Wagad Fault (SWF) in the south and Gedi fault (GF) in the north, and has a maximum elevation of $>400 \mathrm{~m}$ (Biswas and Deshpande 1970). The region is suggested to comprise of several coupled active faults which reactivated after the 2001 Bhuj earthquake (Mandal 2016; Singh et al. 2016). Biswas (2005) inferred that the south dipping SWF is a step-over fault of the KMF in the east, was the source of the 2001 Bhuj earthquake. Seismicity distribution of the area shows that a large number of aftershocks ( $\mathrm{Mw} 2.2-5.7$ ) occurred in the Wagad area with focal depths ranging from 10 to $40 \mathrm{~km}$ (Singh et al. 2016). Lithologically, the terrain is dominated by Jurassic and Cretaceous sandstone, shale and limestone with some outcrop of Tertiary limestone and sandstone in the north and southeast of Wagad (Biswas and Deshpande 1970).

The southern part of the highland, demarcated by the SWF zone is much faulted and appears to have been fragmented into several wedge blocks bounded by converging and diverging faults (figure 2) (Kothyari et al. 2016). The geometry of the SWF zone is very complex due to crustal shearing on both sides of the main fault (SWF) and several domes and anticlinal structures have developed within the fault zone. The upthrown block of the zone has Cretaceous shale, sandstone and glauconitic and micaceous sandstone and the foot wall comprises shale interbedded with marl and miliolitic limestone of CenozoicTertiary age (Kothyari et al. 2016).

In the western part of the highland, two fault branches of SWF are the Adhoi and the Kanthkot faults. The Chitrod and Khanpar faults lie in the central part (figure 2). Several other branches faults, namely Lakadiya, Lakhiasar, Kidiyanagaru and Kanmer faults (Biswas 1993; Kothyari et al. 2016) faults are mapped in the region and are inferred to be developed due to reactivation of SWF. These faults are collectively called the South Wagad Fault (SWF) system (Kothyari et al. 2016). The faults are inferred to be both synthetic and antithetic to the SWF. It is also observed that most of these younger faults were activated after the 2001 main shock (Kothyari et al. 2016). Talwani and Gangopadhya (2003) opined that the presence of intersecting fault zones, particularly in the stable continental region could represent the

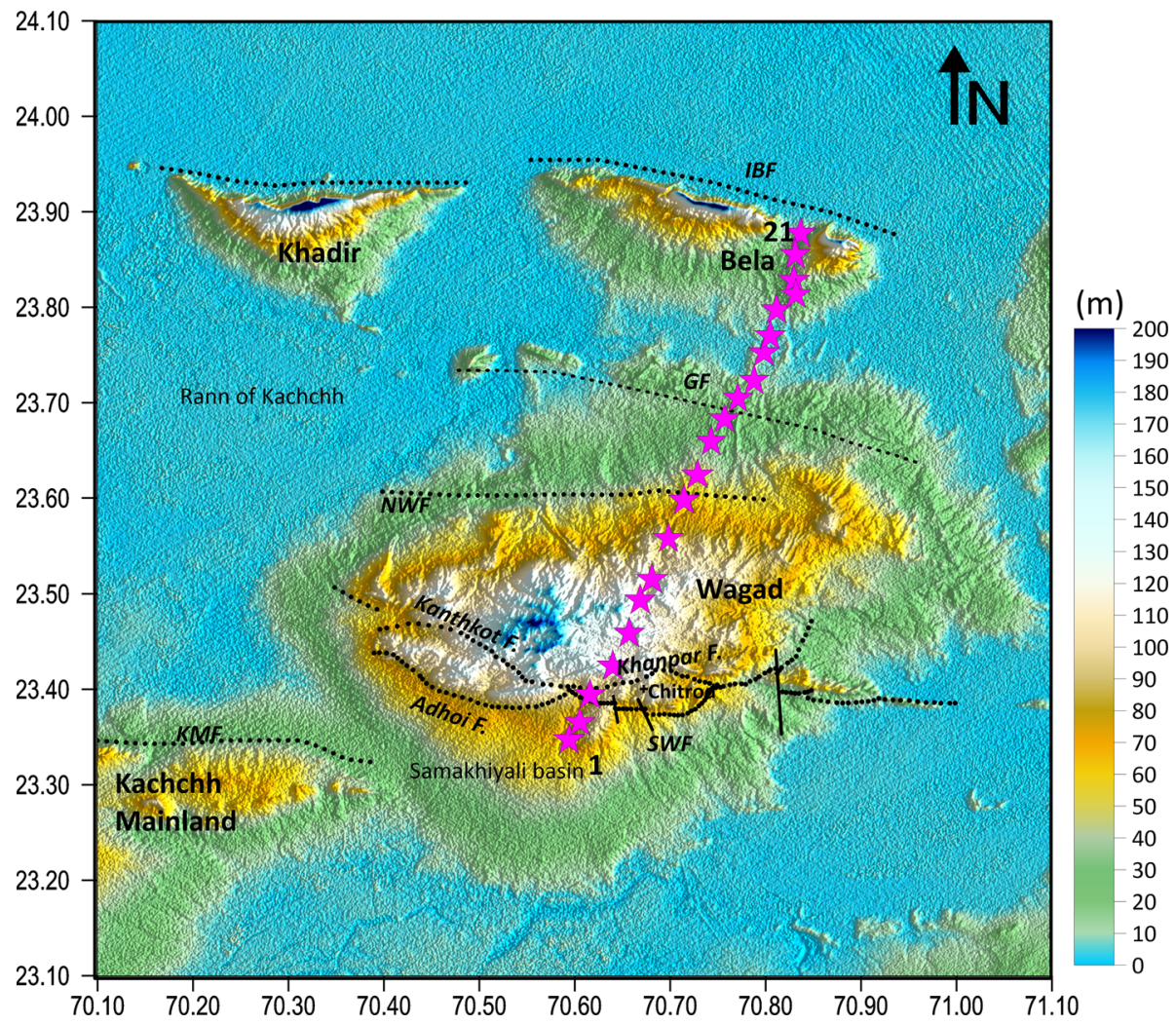

Figure 2. Topographic map of the Wagad highland and its surrounding areas with major faults. (The branch faults of the SWF are taken from Biswas 2016). The TDEM sites are shown with stars. 
zones of stress accumulation and might be probable location for strong earthquakes.

\section{TDEM field survey and data processing}

We carried out the fixed in-loop TDEM soundings at 21 sites in the eastern part of the Kachchh basin (figure 1) for mapping shallow-subsurface structure and distinct lateral and vertical geological contacts in terms of electrical resistivity. The survey transect crosses the various geological terrains bounded by faults, e.g., SWF, NWF and GF (figures 1 and 2). We used Zonge (USA) made data acquisition system comprises the GDP-32 receiver, transmitter (ZT-30), transmitter controller (XMT) and a receiver antenna. During the TDEM survey, a primary electromagnetic field is generated by a $100 \mathrm{~m}$ sided transmitter loop (single turn) laid on the ground, through which alternating current of $9.2 \mathrm{amp}$ is passed with equal periods of time-on and time-off, at various frequencies ranging from 1 to $32 \mathrm{~Hz}$ (Nabighian and Macnae 1991; McNeill 1994). A receiver located near the center of the transmitter loop recorded the secondary vertical magnetic fields $(\mathrm{Hz})$ in terms of the induced voltage (in nanovolts $/ \mathrm{m}^{2}$ ) during the time-off period at 31 discrete time intervals ranging from a few $\mu$ s to a few ms. The window lengths for the different transmitter frequencies are listed in table 1.

Several transient decay measurements are made, and the measurements are stacked to improve signal to noise ratio. To reduce the influence of EM noise, the recorded transients are stacked over a number of cycles (512, 256 and 128 cycles) (Mills et al. 1988; Goldman et al. 1991; McNeill 1994). We recorded data at 32, 16 and $8 \mathrm{~Hz}$ (high frequencies) currents for shallow depths and low frequencies (4, 2 and $1 \mathrm{~Hz}$ ) for deep probing.

Apparent resistivity is computed from the recorded voltage (magnetic field) in the receiver

Table 1. The windows lengths for the different transmitter frequencies.

\begin{tabular}{lccc}
\hline \multirow{2}{*}{$\begin{array}{c}\text { Sl. } \\
\text { no. }\end{array}$} & Frequency & First $(\mu \mathrm{s})$ & Last $(\mathrm{ms})$ \\
\cline { 3 - 4 } 1 & 32 & 30.5 & 6.07 \\
2 & 16 & 30.5 & 12.1 \\
3 & 8 & 30.5 & 24.2 \\
4 & 4 & 30.5 & 48.4 \\
5 & 2 & 61.0 & 96.7 \\
6 & 1 & 121.1 & 193.5 \\
\hline
\end{tabular}

coil and the current injected into the transmitter loop (equation 1). Apparent resistivity at late times can be calculated using the formulae (Nabighian and Macnae 1991)

$$
\rho_{a}=\left(\frac{I A_{T} A_{R}}{V}\right)^{2 / 3}\left(\frac{1}{t}\right)^{5 / 3} * 6.3219 E-3 \Omega \mathrm{m} .
$$

$A_{T}$ and $A_{R}$ are the transmitter and receiver moments in square meters, $I$ is the transmitter current, $V$ is the voltage in microvolts, $t$ is time in milliseconds and $\rho_{a}$ is the apparent resistivity in $\Omega \mathrm{m}$. In general, early time windows may have been saturated (same or similar magnitudes for the first few windows). We removed the early-time saturated windows as well as late-time noise windows (Civico et al. 2017). The decay curves at various transmitter frequencies $(32,16,8,4$, and $2 \mathrm{~Hz})$ and corresponding apparent resistivity curves as a function of time for 20 sites along the profile are shown in figure 3.

\section{One dimensional (1-D) inversion}

The measured transient decay and estimated apparent resistivities are used to model the depth and subsurface resistivity of the underlying structure. We choose the processed data at $4 \mathrm{~Hz}$ transmitter frequencies as the data are less erroneous at late times (>10 ms). The good quality late time data can give deeper information and for too low frequencies, the late time data are many times noisy due to energy dissipation. To maintain the tradeoff between deeper information and quality of the data we have chosen the data at $4 \mathrm{~Hz}$ transmitter frequency with time interval of $62.5 \mathrm{msec}$ to accurately measure the late time transient amplitudes. One dimensional inverse modelling is performed considering the horizontally layered earth model with homogeneous and isotropic layers (Mills et al. 1988). Topographic variations across the profile are incorporated during the inversion routine. To have a slight better near surface resolution for the central loop soundings, we used intermediate to late time gates and omitted first biased gates from the offset measurements due to sign reversal or the anomalous decay of the secondary magnetic field (Villani et al. 2015).

For the present study, we used STEMINV (Zonge, USA) program to estimate layered-earth resistivity models. The algorithm uses an iterating 

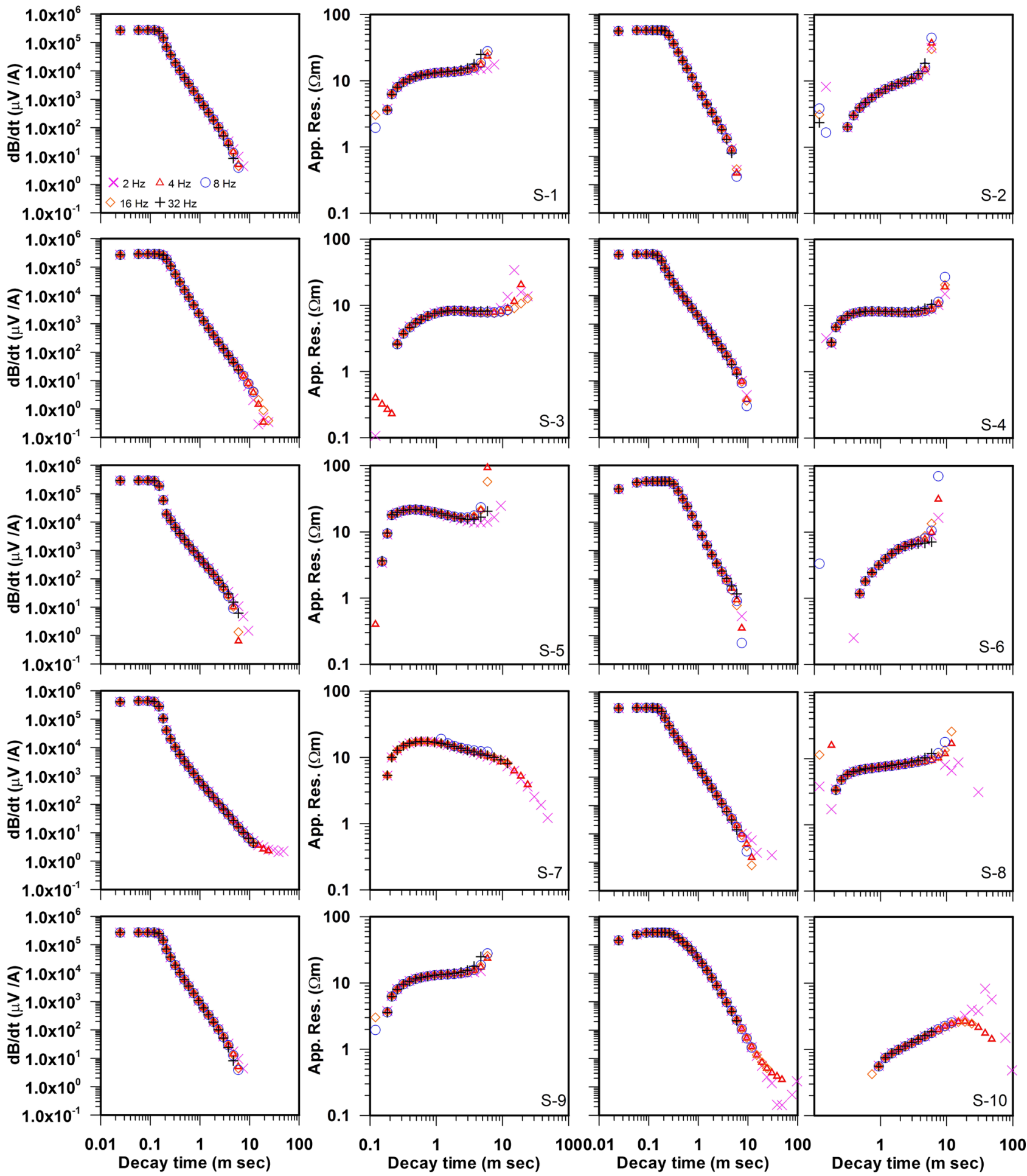

Figure 3. Transient decay and the computed apparent resistivity curves for twenty sites along the profile.

best-fit algorithm to minimize the RMS residuals between the observed and calculated rate of magnetic field reflected as the induced voltage for each station to determine the parameters of a layeredearth model. After generating the initial model, data points that are either anomalous or could not fit to any earth model due to large error bars are selectively discarded from the voltage vs. time decay curve. After removing the anomalous points, the inversion is re-executed to create the best possible model. Total RMS error is calculated using the formula (MacInnes and Raymond 2001) 

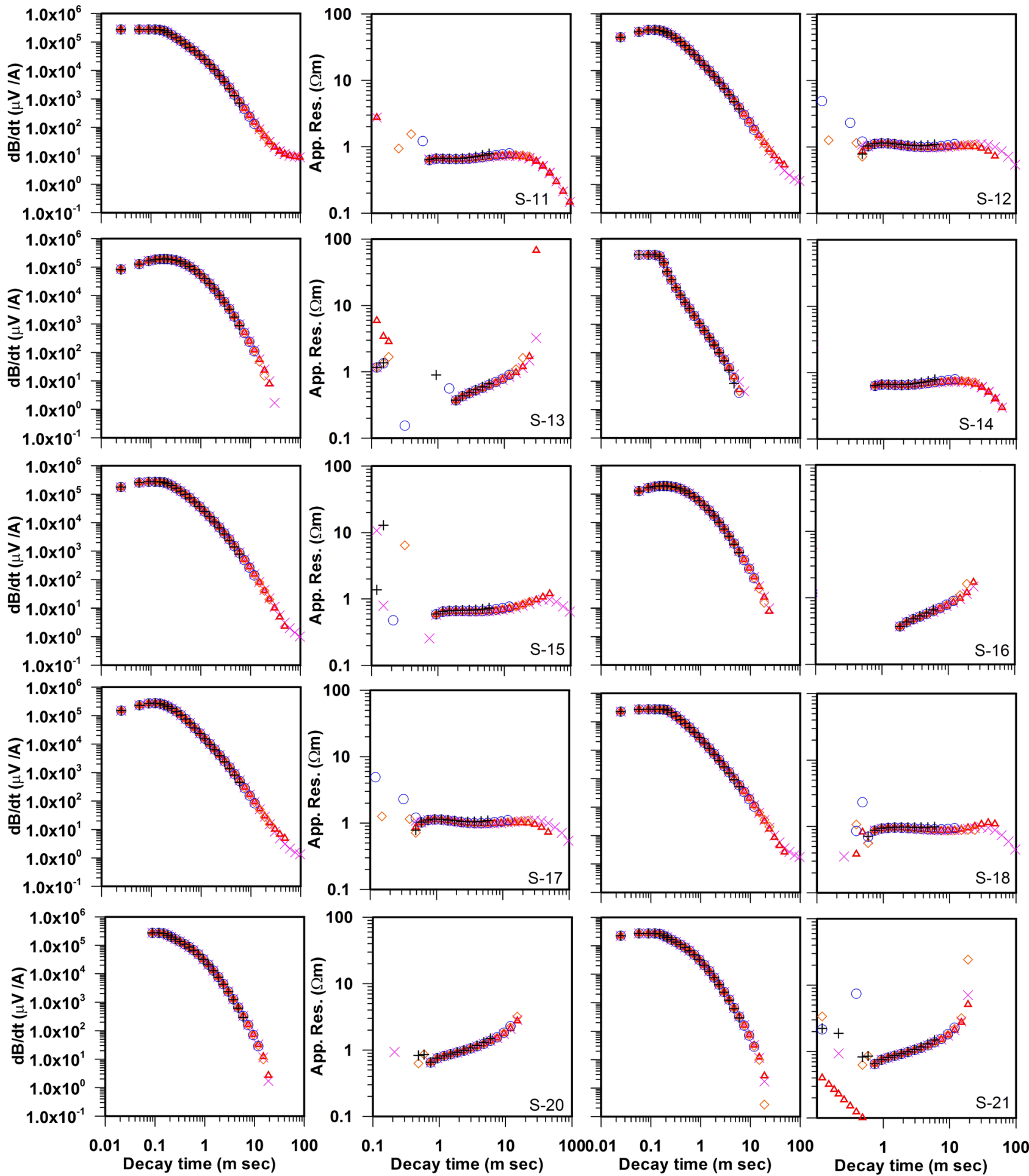

Figure 3. (Continued.)

$$
\begin{aligned}
\varepsilon_{\text {total }} & =\sqrt{\left(\varepsilon_{\text {data }}^{2}+\varepsilon_{\text {model }}^{2}\right) / n_{\mathrm{obs}}}, \\
\varepsilon_{\text {data }^{2}} & =\sum_{i=1}^{n_{\text {obs }}}\left(\frac{d_{o_{i}}-d_{m_{i}}}{d_{\mathrm{err}_{i}}}\right)^{2}
\end{aligned}
$$

$$
\begin{aligned}
\varepsilon_{\text {model }^{2}}= & d p W^{2} \sum_{j=1}^{n z}\left(\frac{p_{j}^{k}-p_{j}^{o}}{p_{\mathrm{err}_{j}}}\right)^{2} \\
& +d z W^{2} \sum_{j=2}^{n z}\left(p_{j}^{k}-p_{j-1}^{k}\right)^{2} .
\end{aligned}
$$




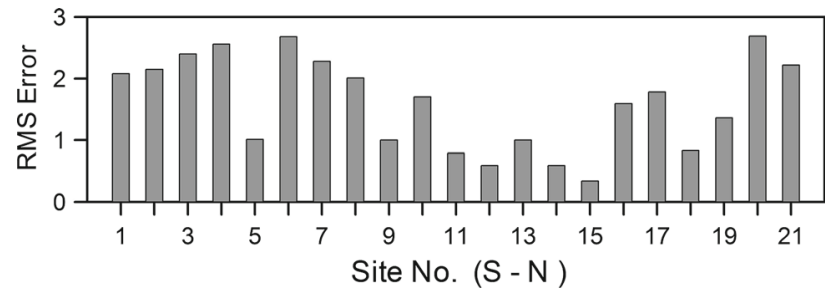

Figure 4. Figure showing the site wise RMS errors.

Here, $n_{\text {obs }}$ is the number of observed data values and $n z$ is the number of layers per station in inversion model. $d_{o_{i}}$ and $d_{m_{i}}$ are the observed and calculated data $(\mathrm{dB} / \mathrm{dt})$, respectively. $d_{\mathrm{err}_{i}}$ and $p_{\operatorname{err}_{j}}$ are the observed data error and inversion model error respectively. $p_{j}^{o}$ and $p_{j}^{k}$ are stating model parameter $[\log ($ resistivity) $]$ and model parameter after $k$ th iteration respectively. $d p W$ and $d z W$ are the relative weight given for starting model and vertical smoothness constraint, respectively.

The total RMS error between observed and modelled TDEM response are less than 2.0 for most of the sites. The total RMS error for each site is shown in figure 4 . The observed and calculated, along with model parameters (resistivity and depth) for 18 sites are shown in figure 5 .

\section{Results and discussion}

One dimensional inversion models of all 21 sites are used to create color-filled resistivity section (figure 6) across the profile. The average RMS error for the section is 1.60. The resistivity section shows significant variations of shallow resistivity values across the fault zone(s) down to $200 \mathrm{~m}$ revealing complex shallow structure of the Wagad region. We have marked the surface locations of the various active faults (Mandal et al. 2007; Bhattacharya et al. 2013; Kothyari et al. 2016) in the resistivity section (figure 6).

The resistivity values $(\sim 100 \Omega \mathrm{m})$ observed in the southern part of the section up to site 8 suggest the presence of Mesozoic rocks in the Wagad region composed of Wagad sandstone and shale (figure 6). Interestingly, a moderate conducive medium at site 4 and slightly dipping south is observed within the Mesozoic. Previous geological studies by Kothyari et al. (2016) inferred normal faulting in the Mesozoic near the south and north of the Chitrod village and named them as Khanpar fault (KF) and Chitrod fault (CF) (figure 2), respectively, which are considered as a branch faults of the SWF. We infer that the conducive zone below site 3 and 4 could indicate the presence of the Chitrod fault $(\mathrm{CF})$. The faulted blocks are clearly reflected in resistivity section with $100 \Omega \mathrm{m}$ on either side of the fault zone (figure 6). The resistivity section clearly demarcates the upthrown and downthrown blocks of the CF. The upthrown block is made up of Cretaceous shale, sandstone and glauconitic and micaceous sandstone and the downthrown block has the shale interbedded with marl and miliolitic limestone of Cenozoic-Tertiary age (Kothyari et al. 2016). The contact zone might be representing the presence of infill material within the two faulted blocks. We attempted to calculate cumulative vertical throw of the SWF and other faults from the obtained resistivity structure of the across the fault zone (figure 6).

\section{$5.1 S W F$}

The shallow layer of the basin infill across the SWF zone (composed of Khanpar and Chitrod normal faults) has observed to be wedge shaped. The resistivity of the infill material with thickness $\sim 15-20$ $\mathrm{m}$ is less than $20 \Omega \mathrm{m}$. We infer that the zone might comprise unconsolidated river deposits (fluvial sediments). We suggest that the deposition of sediments within the wedge might represents the syntectonic growth of the alluvial-fan, filling the accommodation space provided by the hanging wall subsidence. Considering the present day elevation, we estimate a cumulative throw of $60-65 \mathrm{~m}$ for the SWF splays, i.e., $\mathrm{KF}$ and $\mathrm{CF}$; taking into account the difference of basement elevation of the footwall and hanging wall. Based on TDEM soundings, we suggest that the basement rock occurs at $\sim 75-80 \mathrm{~m}$ depth in the footwall of the KF (figure 6).

\section{$5.2 N W F$}

Based on surface geological investigation, McCalpin and Thakkar (2003) have imaged a major morphological features in the Bharudia and named it as Bharudia fault, later described by Mandal et al. (2004) as the North Wagad Fault (NWF) zone. The fault is inferred as a sinuous hanging wall collapse scarp, where the northern part of the scarp is buried by the Quaternary deposits. The sharp resistivity contrast observed across the sites 8 and 9 suggests the contact zone of Mesozoic and Tertiary formations probably representing the presence of the NWF. The fault zone comprises the Tertiary deposits with small content of 


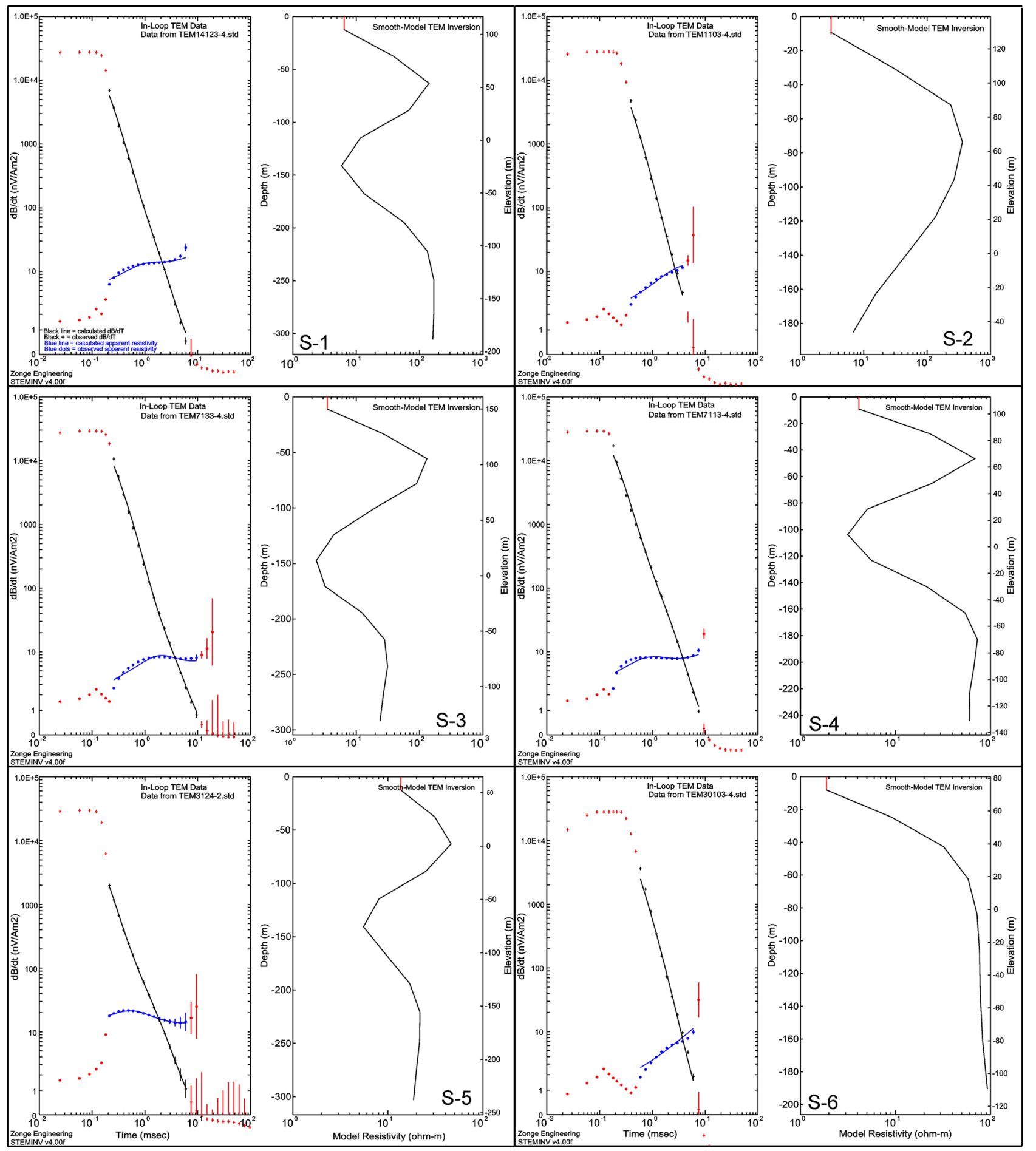

Figure 5. Observed magnetic field values for 18 sites (short horizontal dash and a vertical error bar) along with data (solid black) estimated by the model obtained from inversion (right panel). Omitted data are shown in red.

clay or/and groundwater. The disposition/vertical off set of the two fault blocks is estimated to be about $55-60 \mathrm{~m}$ across the fault zone, which is significantly less compared to the SWF (figure 6). It was opined the NWF is reactivated after the 2001 Bhuj earthquake (Mandal et al. 2007; Mandal 2016), the cumulative throw of the fault blocks is observed to be less compared to the branch fault of SWF. However, the sedimentary deposition over the NWF zone is observed to be high $(>20 \mathrm{~m})$ compared to the SWF (figure 6) zone strengthening the previous observations that the fault has been buried over the Quaternary sediments. Greater Quaternary deposits might also 


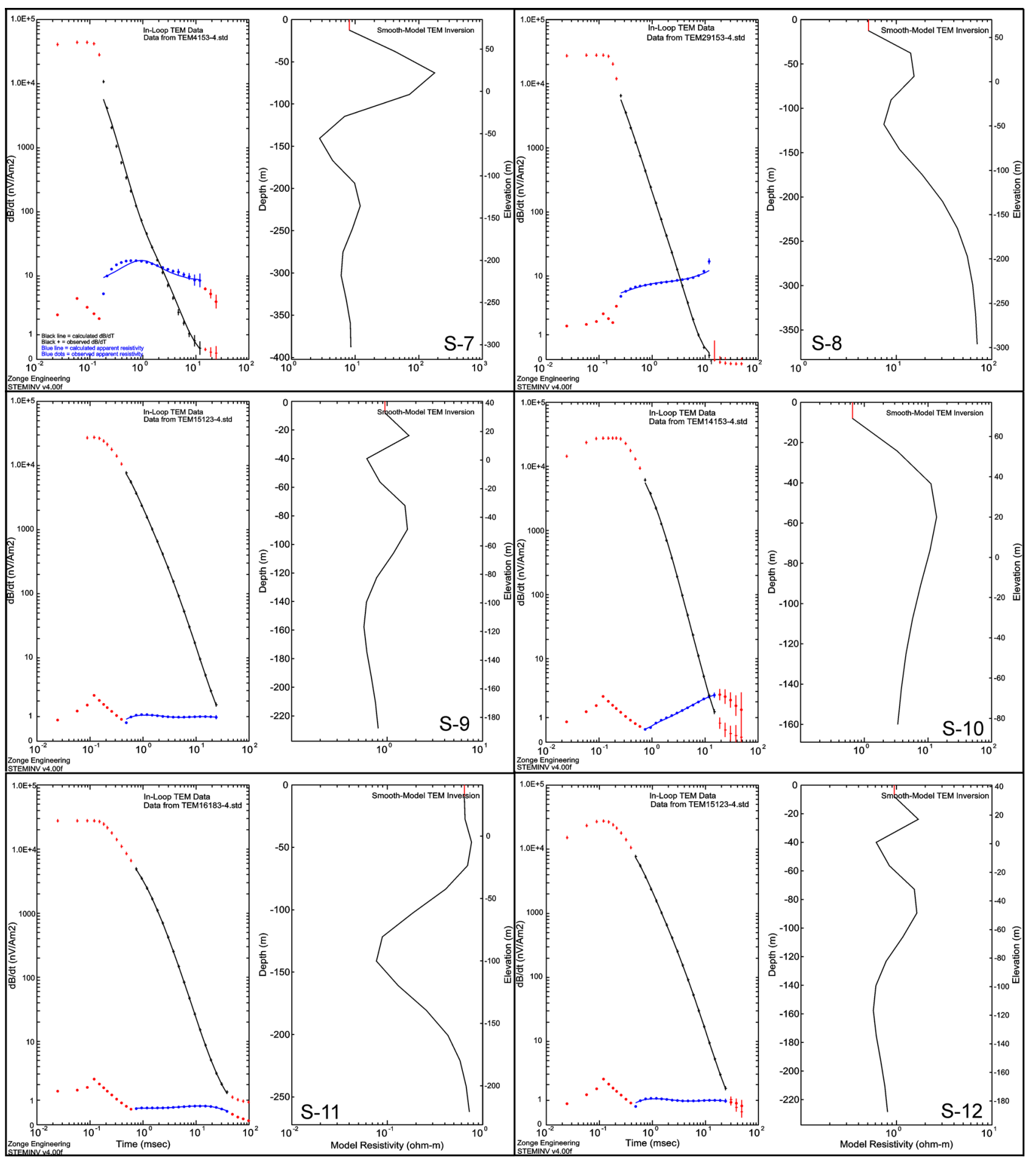

Figure 5. (Continued.)

indicate the greater activity of the NWF in recent past compared to the branch faults of the SWF.

\subsection{Gedi fault}

The sharp resistivity contrast of observed across the sites 10, 11 and 12 in the delineated section corresponds to the Gedi fault, which separates the younger and older formations, i.e., Quaternary to Tertiary. The low resistivity zone is likely related to the fault fractured zone with high content of fluids (probably water at shallower depths) (Electromagnetic Research Group 1982). The wide low resistive zone observed in the section is possibly caused by relatively low degree of fracture, whereas the extremely high conducting band seems 


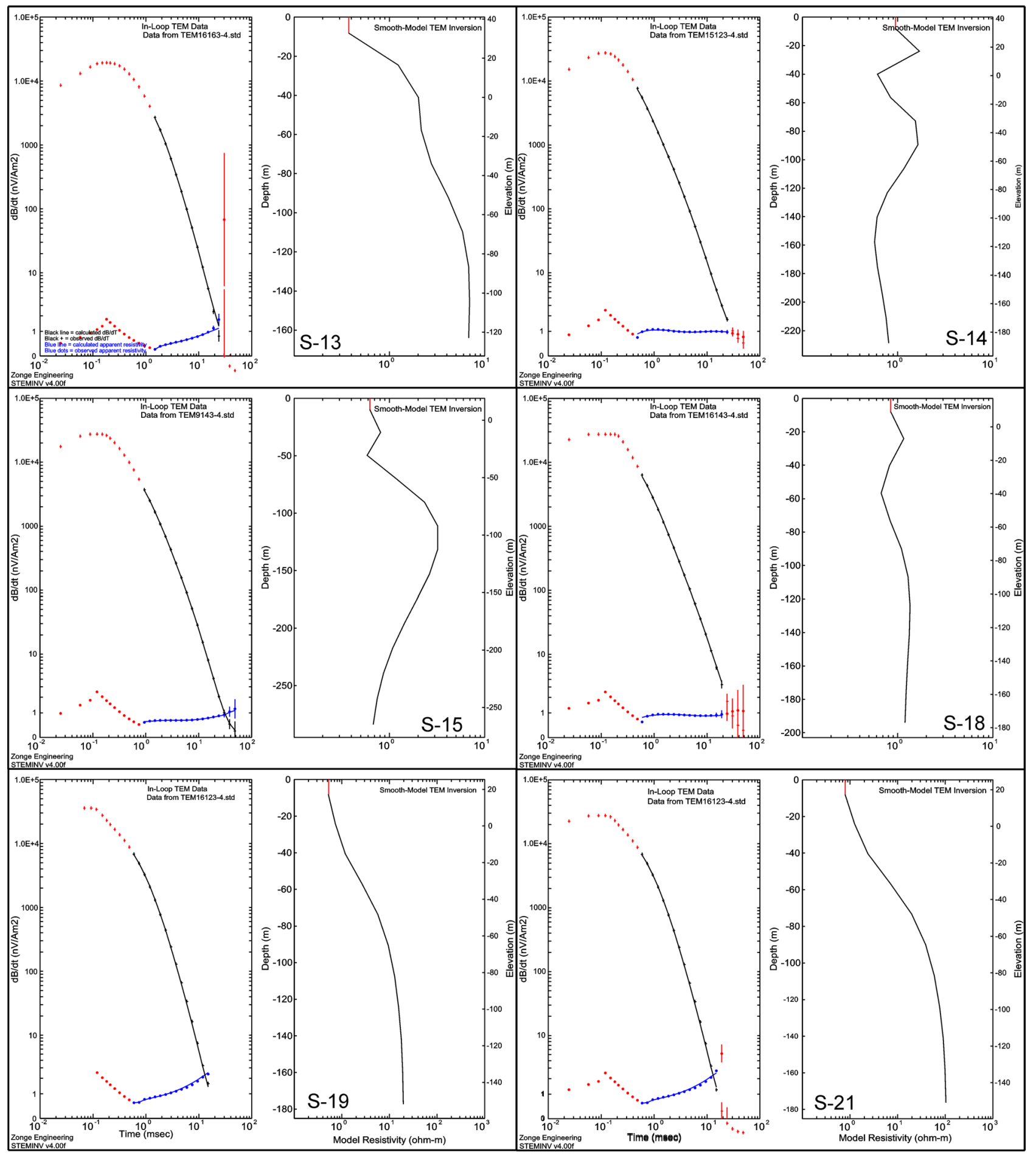

Figure 5. (Continued.)

associated with the fault plane, along which clay minerals have developed along the fractured zone. Further, the Gedi fault zone is very close to the Rann of Kachchh, there is a possibility of infiltration/saturation of the fracture zone with marine water having high salinity along with deposition of clay. The vertical disposition of blocks could have attributed to the dominate strike-slip nature of faulting across the GF. Across the GF, the derived resistivity section indicates least block displacements (45-50 m) (figure 6). The small vertical disposition of blocks could have attributed to either due to dominate strike-slip nature of faulting in addition to normal or more activeness of 


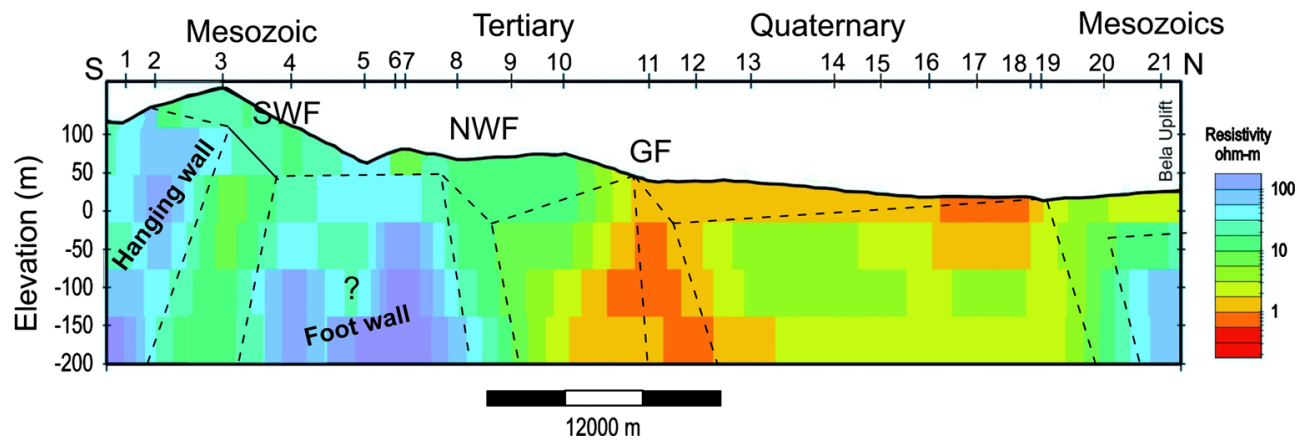

Figure 6. Near surface resistivity section across the SWF and GF zones.
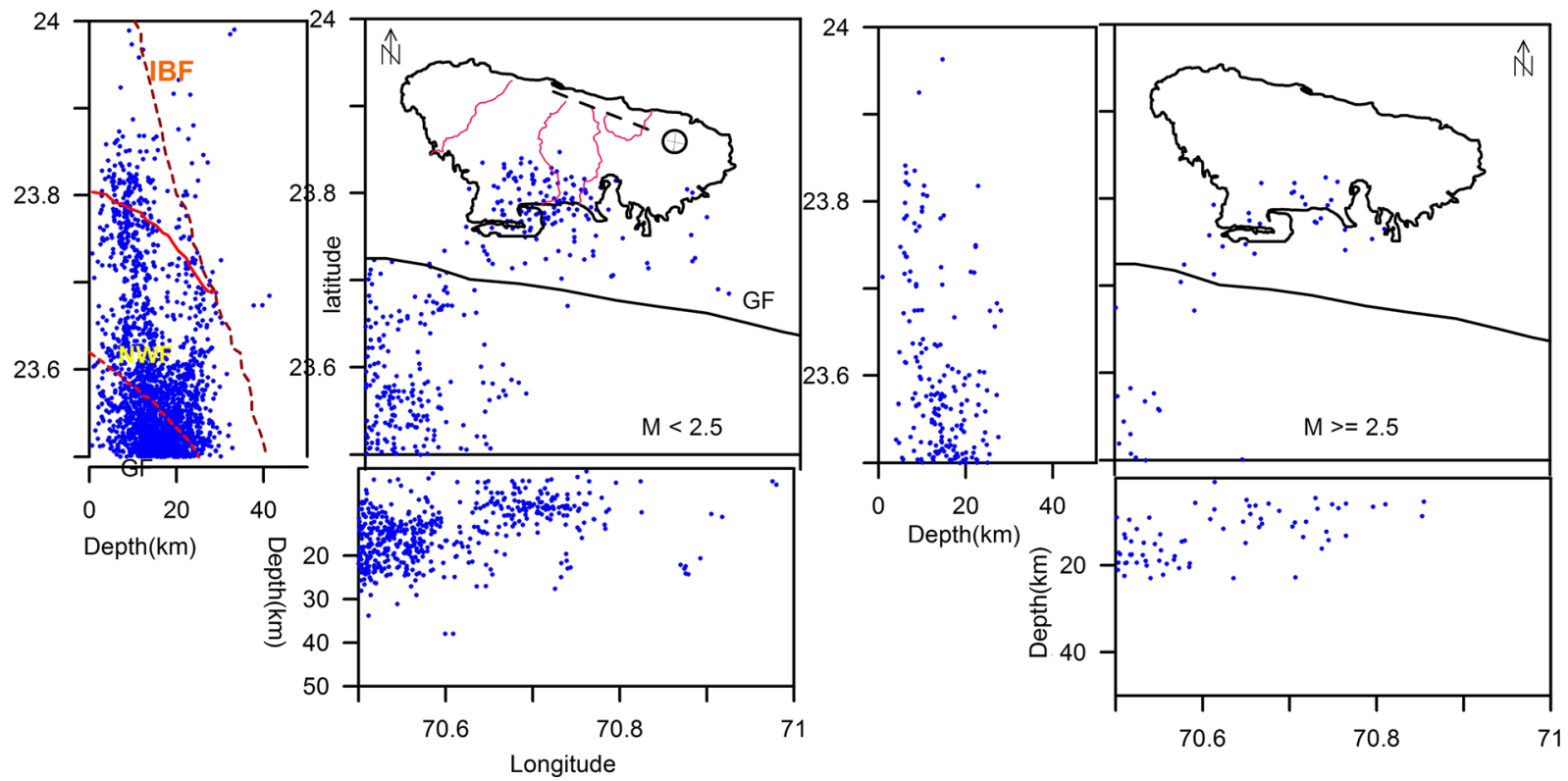

Figure 7. Seismicity (during 2008-2015) distribution map across the Bela island.

NWF compared to GF during the recent geological past. Similar to NWF, the GF is inferred to be reactivated (Bhattacharya et al. 2013) after the Bhuj earthquake. However, data at grid pattern around the GF could give better information on the lateral lithological changes across the fault zone.

\subsection{Rann sediments}

The low resistivity values observed in northern part of the Gedi fault infers the Quaternary sedimentary formations, mainly of mud and salt-flats (Rann sediments) between sites 13 to 19 (figure 6). The Rann sediments are observed as highly conductive $(<5$ $\Omega \mathrm{m})$ zone in the entire depth section. However, a comparatively less conductive zone $(\sim 10 \Omega \mathrm{m})$ is observed between the sites 13 to 15 . We infer that that this could be an aquifer zone within the Tertiary deposits, trapped in-between the two uplifted terrains. However, the presence of the aquifer zone and its linkage with any paleochannels of the region is needed to be studied in detail.

Between sites 4 and 5, we observe a moderate conductive zone within the foot wall of the SWF/CF block. In view of continued seismicity of the region and active deformation of the Wagad uplift, we opined that this moderately conductive zone might be representing a fractured zone within the highland. However, some more TDEM points are required to further characterize the zone. In the northern most part of the profile, we observe another resistivity contrast reflecting the geological contact between the Rann-sediments and the Bela uplift that composed of Mesozoic. The Bela island bounded by IBF at the north and GF at its south. The Bela island suggested be northerly uplifted and dipping towards the GF (Biswas 2016). High seismic activity (figure 7) in the southern Bela unit and elevation differences suggest the activeness of these faults. We, therefore, speculate that 
the geological contact could be considered as a branch fault of GF developed due to the rupture created by the seismic activity on southern Bela highland.

From the resistivity model (figure 6), it is evident that the traces of the SWF and GF are seen up to the surface. This affirms that these faults are responsible for the ongoing Holocene deformation in the region, suggesting the active nature of the faults. The significant heterogeneities across the SWF and GF zones in the shallow subsurface levels as observed in deep geophysical studies (Mandal 2016; Singh et al. 2016; Pavan Kumar et al. 2017a, b) could be responsible for the accumulation of large crustal strain that results in high seismic activity in the KRB. However, the buried and active nature of the faults in terms of seismicity needs deep geophysical studies, particularly magnetotellurics investigation to map and understand the deep architecture of the fault zone.

\section{Conclusions}

Resistivity section obtained after combining one dimensional models of the 21 sites acquired across the various fault zones in the eastern Kachchh basin suggests the significant variations of shallow resistivity values across the fault zone(s) down to $200 \mathrm{~m}$. The shallow layer of the basin infill across the SWF and NWF has a wedge shape and represent the ongoing syntectonic sedimentation due to the movement of the fault blocks. The resistivity model indicates a minimal $\sim 60-65 \mathrm{~m}$, and $50-55$ $m$ estimate of the cumulative throw of the SWF and NWF, respectively in the investigated section. Across the GF, the derived resistivity section indicates least block displacements compared to the NWF zone, indicating more activeness of NWF compared to GF. The results from the study affirms the ongoing Holocene deformation in the region signifying the active nature of the faults, which is also supported by deep and shallow geophysical constrains. Interdisciplinary studies, including shallow geophysical, geomorphological and paleoseismological studies are essential to characterize the active faults in the area and precise subsurface studies shall document the successive tectonic events and related landform development. The study highlights the efficacy of the TDEM studies in structural geology and morphotectonic studies in the active intraplate region.

\section{Acknowledgements}

We are very thankful to the Director General and the Director, ISR for the kind permission to publish the present work. We thank E Mahender, Dilip Singh and Prutul Patel for their help in TDEM field survey. We are grateful to the anonymous reviewer for the constructive suggestions which enhances the quality of the manuscript.

\section{References}

Bhattacharya F, Rastogi B K and Kothyari G 2013 Morphometric evidence of seismicity around the Wagad and Gedi Faults, eastern Kachchh, Gujarat, India; J. Geol. Soc. India 81 113-121.

Biswas S K and Khattri K N 2002 A geological study of earthquakes in Kutch, Gujarat, India; J. Geol. Soc. India 60 131-142.

Biswas S K 1993 Geology of Kutch; KDM Institute of Petroleum Exploration, Dehradun, 450p.

Biswas S K 2016 Tectonic framework, structure and tectonic evolution of Kutch Basin, western India; Spec. Publ. Geol. Soc. India 6 129-150.

Biswas S K 2005 A review of structure and tectonics of Kutch basin, western India, with special reference to earthquakes; Curr. Sci. 88 1592-1600.

Biswas S K and Deshpande S V 1970 Geological and tectonic maps of Kutch; ONGC Bull. 7 115-116.

Chandrasekhar D V, Burgmann R, Reddy C D, Sunil P S and Schmidt D A 2009 Weak mantle in NW India probed by geodetic measurements following the 2001 Bhuj earthquake; Earth Planet. Sci. Lett. 280 229-235.

Chandrasekhar E, Mathew G and Harinarayana T 2012 A new hypothesis for the deep subsurface structures near the Bhuj 2001 earthquake (Mw 7.6) hypocenter zone and its tectonic implications; Geophys. J. Int. 190 761-768.

Chowksey V, Maurya D M, Joshi J, Khonde N, Das A and Chamyal L S 2011 Lithostratigraphic development and neotectonic significance of the Quaternary sediments along the Kachchh Mainland Fault (KMF) zone, Western India; J. Earth Syst. Sci. 120(6) 979-999.

Civico R, Sapia V, Di Giulio G, Villani F, Pucci S, Baccheschi P, Amoroso S, Cantore L, Di Naccio D, Hailemikael S, Smedile M, Vassallo M, Marchetti M and Pantosti D 2017 Geometry and evolution of a fault-controlled Quaternary basin by means of TDEM and single station ambient vibration surveys: the example of the 2009 L'Aquila earthquake area; J. Geophys. Res., https://doi.org/10.1002/ 2016JB013451.

Electromagnetic Research Group for Active Fault 1982 Low electrical resistivity along an active fault, the Yamasaki fault; J. Geomag. Geoelectric. 34 103-127.

Goldman M, Gilad D, Rouen A and Melloul A 1991 Mapping of seawater intrusion into the coastal aquifer of Israel by the time domain electromagnetic method; Geoexploration 28 153- 174.

Kayal J R, Zhao D, Mishra O P, De R and Singh O P 2002 The 2001 Bhuj earthquake: Tomographic evidence for 
fluids at the hypocenter and its implications for rupture nucleation; Geophys. Res. Lett. 29(24) 2512, https://doi. org/10.1029/2002gj015177.

Kothyari G C, Dumka R K, Singh A P, Chauhan G, Thakkar M G and Biswas S K 2016 Tectonic evolution and stress pattern of South Wagad Fault at the Kachchh Rift Basin in western India; Geol. Mag., https://doi.org/10.1017/ S0016756816000509.

MacInnes S and Raymond M 2001 ZONGE data processing smooth-model TEM inversion, version 3.00, Zonge Engineering and Research Organization, Inc., http://www. zonge.com.au/docs/software/steminv.pdf.

Malik J N, Sohoni P S, Merh S S and Karanth R V 2001 Active tectonic control on alluvial fan architecture along the Kachchh Mainland Hill Range, Western India; Zeithschrift fur Geomorphologie 45 81-100.

Mandal P 2016 Variations of seismic velocities in the Kachchh rift zone, Gujarat, India, during 2001-2013; Tectonophys. 672 68-86.

Mandal P, Chadha R K, Raju I P, Kumar N, Satyamurty C, Narsaiah R and Maji A 2007 Coulomb static stress variations in the Kachchh, Gujarat, India: implications for the occurrences of two recent earthquakes $(\mathrm{Mw}=5.6)$ in the 2001 Bhuj earthquake region; Geophys. J. Int. 169 281-285.

Mandal P, Rastogi B K, Satyanarayana H V S and Kousalya M 2004 Results from local earthquake velocity tomography: Implications toward the source process involved in generating the 2001 Bhuj Earthquake in the lower crust beneath Kachchh (India); Bull. Seismol. Soc. Am. 94(2) 633-649.

Mathew G, Singhvi A K and Karanth R V 2006 Luminescence chronometry and geomorphic evidence of active fold growth along the Kachchh Mainland Fault (KMF), Kachchh, India: Seismotectonic implications; Tectonophys. 422 71-87.

Maurya D M, Chouksey V, Joshi P N and Chamyal L S 2013 Application of GPR for delineating the neotectonic setting and shallow subsurface nature of the seismically active Gedi fault, Kachchh, western India; J. Geophys. Eng. 10 034006, https://doi.org/10.1088/1742-2132/10/ $3 / 034006$.

McCalpin J P and Thakkar M G 2003 Bhuj-Kachchh earthquake: Surface faulting and its relation with neotectonics and regional structures, Gujarat, Western India; Ann. Geophys. 46 937-956.

McNeill J D 1994 Principles and application of time domain electromagnetic techniques for resistivity sounding; Geonics technical note TN-27, Mississauga, Ontario, pp. 1-15.

Merh S S 1995 Geology of Gujarat; Geological Society of India (GSI).

Mills T, Hoekstra P, Blohm M and Evans L 1988 Time domain electromagnetic soundings for mapping seawater intrusion in Monterey County, California; Ground Water 26 771-782.

Mithila V and Bansal B 2016 Active fault research in India: Achievements and future perspective; Geomat. Nat. Haz. Risk 7(1) 65-84.
Nabighian M N and Macnae J C 1991 Time domain electromagnetic prospecting methods; In: Electromagnetic Methods in Applied Geophysics (ed.) Nabighian M N, Society of Exploration Geophysicists, pp. 427-520.

Naganjaneyulu K, Ledo J J and Queralt P 2010 Deep crustal electromagnetic structure of Bhuj earthquake region (India) and its implications; Geol Acta 18 83-97.

Patidar A K, Maurya D M, Thakkar M G and Chamyal L S 2008 Evidence of neotectonic reactivation of the Katrol Hill Fault during late Quaternary and its GPR characterization; Curr. Sci. 94 338-346.

Patidar A K, Maurya D M, Thakkar M G and Chamyal L S 2007 Fluvial geomorphology and neotectonic activity based on field and GPR data, Katrol hill range, Kachchh, Western India; Quat. Int. 159 74-92.

Pavan Kumar G, Mahender E, Singh Y K, Mahesh P and Kapil Mohan 2016 Delineation of aquifer layer along Anjar-Rapar Corridor, eastern Kachchh basin, Gujarat using electromagnetic investigations; J. Indian. Geophys. Union 20(2) 201-208.

Pavan Kumar G, Choudhary V K, Mehul Nagar E, Mahendhar, Singh D, Patel P and Mahesh P 2017 Magnetotelluric impedance tensor analysis for identification of transverse tectonic feature in the Wagad uplift, Kachchh, northwest India; J. Earth Syst. Sci., https://doi.org/10.1007/ s12040-017-0851-x.

Pavan Kumar G, Mahesh P, Mehul Nagar E, Mahender, Kumar V, Kapil Mohan and Ravi Kumar M 2017 Role of deep crustal fluids in the genesis of intraplate earthquakes in the Kachchh region, northwestern India; Geophys. Res. Lett. 44, https://doi.org/10.1002/2017GL072936.

Rajendran C P, Rajendran K, Thakkar M and Goyal B 2008 Assessing the previous activity at the source zone of the 2001 Bhuj earthquake based on the near-source and distant paleo-seismological indicators; J. Geophys. Res. 113 B05311, https://doi.org/10.1029/2006JB004845.

Rastogi B K, Mandal P and Biswas S K 2014 Seismogenesis of earthquakes occurring in the ancient rift basin of Kachchh, Western India; In: Intraplate Earthquakes (ed.) Talwani P, Cambridge University Press, Cambridge, pp. 126-161.

Rastogi B K, Agarwal S K, Rao N and Choudhury P 2012 Triggered/migrated seismicity due to the $2001 \mathrm{Mw} 7.7$ Bhuj earthquake, Western India; Nat. Hazards. 33(5), https://doi.org/10.1007/s11069-011-0083-3.

Singh A P, Zhao L, Kumar S and Mishra S 2016 Inversions for earthquake focal mechanisms and regional stress in the Kachchh Rift Basin, Western India: Tectonic implications; J. Asian Earth. Sci. 117 269-283.

Talwani P 2016 On the nature of intraplate earthquakes; J. Seismol. 21(1) 47-68, https://doi.org/10. 1007/s10950-016-9582-8.

Villani F, Tulliani V, Sapia V, Fierro E, Civico R and Pantosti D 2015 Shallow subsurface imaging of Piano di Pezza active normal fault (Central Italy) by high resolution refraction and electrical resistivity tomography coupled with time domain electromagnetic data; Geophys. J. Int. 203 1482-1494. 